\title{
Quality of Life among Saudi Diabetics
}

\author{
Fahad S. Al-Shehri \\ Joint Program of Family Medicine, Abha, KSA \\ Email: fahdshar@hotmail.com
}

Received 9 June 2014; revised 5 July 2014; accepted 1 August 2014

Copyright (C) 2014 by author and Scientific Research Publishing Inc.

This work is licensed under the Creative Commons Attribution International License (CC BY). http://creativecommons.org/licenses/by/4.0/

c) (i) Open Access

\begin{abstract}
Aim of study: To assess QOL among Saudi diabetics and to identify the possible risk factors associated with lower QOL. Patients and Methods: This study comprised 400 diabetic patients attending the Diabetes Clinic at the University Diabetes Center in Riyadh. They were interviewed using the Audit of Diabetes Dependent QOL (ADDQOL). Results: Most diabetic patients (78.7\%) had negative (i.e., unfavorable) ADDQOL scores. Diabetic patients' age, education and occupation were not significantly associated with their QOL. Female patients had significantly worse QOL than male patients $(p=0.026)$. Married patients had significantly worse QOL compared with non-married patients $(p=0.012)$. Patients with type 2 diabetes had significantly worse QOL than those with type 1 diabetes $(p=0.029)$. Duration of diabetes was not significant factors as regard their $Q O L$, with the worst QOL among those with more than 20 years of diabetes. The degree of diabetes control was significantly and directly associated with QOL score $(p<0.001)$. The worst QOL was expressed among poorly controlled diabetes while the best was among patients with excellent control. QOL of diabetics was less among those who had diabetes complications, i.e., neuropathy $(p=0.03)$, retinopathy $(p<0.001)$, and diabetic foot $(p=0.031)$. However, difference was not significant according to those with nephropathy. Conclusions: QOL of Saudi adult diabetic patients is not favorable. Personal characteristics associated with worse QOL among diabetics include female gender, and being married. Disease characteristics associated with worse QOL include being a type 2 diabetic and those with uncontrolled diabetes. Main complications associated with worse QOL among diabetics include retinopathy, diabetic foot and neuropathy.
\end{abstract}

\section{Keywords}

Quality of Life, Diabetes Mellitus, Retinopathy, Nephropathy, Neuropathy, Diabetic Foot

\section{Introduction and Aim of Study}

As advances in medical technology and new, more aggressive treatments succeeded in increasing survival rates, attention increasingly turned towards the quality of life (QOL) of patients rather than longevity alone. Today, 
QOL assessment measures are routinely used to evaluate the human and financial costs and benefits of different health programs and medical interventions. Health-related QOL (HRQOL) is concerned with QOL within the specific context of health [1].

The prevalence of diabetes mellitus is reaching epidemic proportions in many parts of the world. It is an increasingly important public health concern. In the United States, diabetes is present in $8 \%$ of the adult population, and is associated with a two-fold increase in age-adjusted mortality [2]. In many developing countries, including Saudi Arabia, the incidence of diabetes is increasing and its prevalence is also approaching epidemic proportions [3]. In a national Saudi study to assess prevalence of diabetes mellitus between the ages of 30-70years, Al-Nozha et al. (2004) [4] reported that 4004 out of 16917 (23.7\%) were diagnosed to have diabetes. Diabetes mellitus was more prevalent among Saudis living in urban areas of $25.5 \%$ compared to rural Saudis of $19.5 \%$ ( $\mathrm{p}$ 0.00001). Despite the readily available access to healthcare facilities in KSA, a large number of diabetics 1116 (27.9\%) were unaware of having DM.

Diabetes has detrimental effects on a range of health outcomes including QOL [5]. Almost two decades ago, Stewart et al. (1989) [6] noted that diabetes impairs all dimensions of health except mental health and pain. In a more recent multinational study, diabetes was found to have a notable impact on general health [7]. The magnitude of impact of diabetes on QOL was reported to be equivalent to that of having cardiovascular conditions, cancer and chronic respiratory disease [8].

Several studies have demonstrated that diabetes has a strong negative impact on the HRQOL, especially in the presence of complications [9]-[11]. However, most of the studies on diabetes and QOL have been conducted in developed countries [12] and studies of the QOL in diabetic patients in developing countries are rare [13] [14].

Since patient's perceptions about diabetes and diabetes-related complications may have a significant influence on their QOL, the relationship between QOL and diabetes mellitus should be elucidated. Hence, this study aimed to assess QOL among Saudi diabetics and to identify the possible risk factors associated with lower QOL.

\section{Patients and Methods}

This research followed a hospital-based cross-sectional study design. It was conducted at the "University Diabetes Center" in Riyadh. All diabetic patients who fulfilled the inclusion criteria constituted the study population. These inclusion criteria were: adult Saudi diabetic patients, whose disease duration is more than one year, non-pregnant (for females), living in Riyadh. This study comprised 400 diabetic patients.

All diabetic patients included in the present study were interviewed using the "Audit of Diabetes Dependent Quality Of Life (ADDQOL)”. The ADDQOL was designed by Bradley et al. (1999) [15] to be a reliable and valid instrument for the assessment of QOL. Those who score $\geq 0$ are considered to have good QOL, -0.1 to -2.0 have bad QOL, -2.1 to -4.0 have very bad QOL, while those with scores less than -4.0 have extremely bad QOL.

The questionnaire was translated into simple Arabic language by the researcher. A pilot study was conducted at the Diabetes Clinic at King Abdul-Aziz University Hospital in Riyadh on 40 diabetic patients who were not included into the main study. This pilot study aimed to test the clarity of questionnaire's wording.

Data were collected from patients' records, concerning their demographic characteristics, last HbA1c level. The level of control of diabetes was assessed according the level of $\mathrm{HbA}_{1 \mathrm{C}}$. Those who have their $\mathrm{HbA}_{1 \mathrm{C}}<7$ were considered to have excellent diabetes control, those with 7 - 8 have good control, those with 8.1 - 11 have fair control, while those with $>11$ have poor control [16]. Diabetes complications were identified by presence of retinopathy (assessed by history of visual disturbance, history of cataract and fund us examination by an ophthalmologist), nephropathy (assessed by proteinuria or raised serum urea and creatinine after exclusion of other causes), neuropathy (assessed by a history of numbness or decreased sensation and evidence of decreased sensation or reflexes on neurological examination or evidence of electrophysiological testing). Diabetic foot (assessed by a history of foot care behavior and foot examination for peripheral neuropathy (PN), peripheral vascular disease (PVD), and foot deformities. PN was evaluated using the Semmes-Weinstein monofilament test. PVD was graded by clinical measures and Doppler examination (ankle:brachial index $<0.9$ )

Data analysis was carried out using the Statistical Package for Social Sciences (SPSS ver. 14.0). Descriptive statistics were applied (i.e., frequency, percentage, mean and standard deviation). Difference between mean ADDQOL scores was compared using Student's and ANOVA tests. Significance level was set at $\mathrm{p}<0.05$. 


\section{Results}

Table 1 shows that less than one fourth of diabetic patients had good QOL (85\%, 21.3\%), hence, most diabetic patients (315\%, 78.7\%) had negative (i.e., unfavorable) ADDQOL scores. Almost half of diabetics had their scores ranging from very bad (186\%, 46.5\%) to extremely bad (18\%, 4.5\%).

Table 2 shows that about half of diabetic patients were females (51.8\%), about three fourths aged more than 40 years. Most patients were married (84.5\%). Almost one third of patients were illiterate (30.5\%), while almost two thirds were not working (62.5\%). Diabetic patients' age, education and occupation are not significant variables as regard their QOL. Female patients had significantly worse QOL $(p=0.026)$. Married patients had significantly worse QOL compared with non-married patients $(\mathrm{p}=0.012)$.

Table 3 shows that most patients were type 2 diabetics, whose duration of diabetes was 10 - 20 years in more than half of them (56\%) and treated with oral hypoglycemic (50.5\%). In almost half of cases, diabetes control was favorable, being either excellent (25\%) or good (25.5\%). Complications of diabetes were mainly retinopathy (42.5\%) or neuropathy (28.3\%). Patients with type 2 diabetes had significantly worse QOL than those with type 1 diabetes $(p=0.029)$. QOL was less among diabetics with less than 10 years duration of disease, followed by a relatively better QOL among those with10 - 20 years and then the worse QOL was present among those with more than 20 years of diabetes. Moreover, oral hypoglycemic treatment was associated with relatively better QOL compared with those who were on insulin treatment or those with combined oral hypoglycemic and insulin. However, duration of diabetes as well as the type of treatment was not significant factors as regard their QOL. The degree of control of disease among diabetics was significantly and directly associated with their QOL

Table 1. Distribution of ADDQOL grades.

\begin{tabular}{llcc}
\hline \multicolumn{1}{c}{ ADDQOL Scores } & No. & \% \\
\hline & $\geq 0$ (Good) & 85 & 21.3 \\
$\bullet-0.1$ to $-2.0(\mathrm{Bad})$ & 111 & 27.8 \\
$\bullet-2.1$ to $-4.0($ Very Bad) & 186 & 46.5 \\
$\bullet$ & $<-4.0($ Extremely Bad) & 18 & 4.5 \\
\hline
\end{tabular}

Table 2. Distribution of mean ADDQOL scores according to personal characteristics of study sample.

\begin{tabular}{|c|c|c|c|c|}
\hline Variables & No. & $\%$ & Mean + SD & p-value \\
\hline \multicolumn{5}{|c|}{ Age groups (in years) } \\
\hline$<20$ & 20 & 5.0 & $-1.47+1.52$ & \\
\hline $21-40$ & 81 & 20.3 & $-2.56+2.03$ & \\
\hline $41-60$ & 249 & 62.3 & $-2.55+1.95$ & \\
\hline$>60$ & 50 & 12.5 & $-2.48+2.10$ & 0.121 \\
\hline \multicolumn{5}{|l|}{ Sex: } \\
\hline Females & 207 & 51.8 & $-2.69+2.01$ & \\
\hline Males & 193 & 48.3 & $-2.25+1.92$ & 0.026 \\
\hline \multicolumn{5}{|l|}{ Marital status } \\
\hline Single & 50 & 12.5 & $-1.84+1.61$ & \\
\hline Married & 338 & 84.5 & $-2.61+2.02$ & \\
\hline Divorced & 12 & 3.0 & $-1.61+1.43$ & 0.012 \\
\hline \multicolumn{5}{|l|}{ Education } \\
\hline Illiterate & 122 & 30.5 & $-2.53+1.97$ & \\
\hline School & 187 & 46.8 & $-2.52+2.03$ & \\
\hline University & 91 & 22.8 & $-2.33+1.89$ & 0.718 \\
\hline \multicolumn{5}{|l|}{ Occupation } \\
\hline Governmental & 83 & 20.8 & $-2.32+1.68$ & \\
\hline Business & 16 & 4.0 & $-3.63+2.89$ & \\
\hline Professional & 51 & 12.8 & $-2.32+1.82$ & \\
\hline Unemployed & 250 & 62.5 & $-2.49+2.02$ & 0.097 \\
\hline
\end{tabular}


Table 3. Distribution of mean ADDQOL scores according to disease characteristics.

\begin{tabular}{|c|c|c|c|c|}
\hline Variables & No. & $\%$ & Mean + SD & p-value \\
\hline \multicolumn{5}{|l|}{ Type of diabetes } \\
\hline Type 1 & 57 & 14.3 & $-1.95+1.57$ & \\
\hline Type 2 & 343 & 85.8 & $-2.56+2.03$ & 0.029 \\
\hline \multicolumn{5}{|l|}{ Duration of diabetes (years) } \\
\hline$<10$ & 127 & 31.8 & $-2.40+1.94$ & \\
\hline $10-20$ & 224 & 56.0 & $-2.17+1.95$ & \\
\hline$>20$ & 49 & 12.3 & $-2.72+2.20$ & 0.640 \\
\hline \multicolumn{5}{|l|}{ Diabetes control } \\
\hline Excellent (HbA1C < 7\%) & 100 & 25.0 & $-1.57+1.68$ & \\
\hline Good $(\mathrm{HbA} 1 \mathrm{C}=7 \%-8 \%)$ & 102 & 25.5 & $-2.45+1.79$ & \\
\hline Fair $(\mathrm{HbA} 1 \mathrm{C}=8.1 \%-11 \%)$ & 184 & 46.0 & $-2.88+1.98$ & \\
\hline Poor (HbA1C > 11\%) & 14 & 3.5 & $-3.98+2.73$ & $<0.001$ \\
\hline \multicolumn{5}{|l|}{ Diabetes complications } \\
\hline \multicolumn{5}{|l|}{ Neuropathy } \\
\hline Yes & 113 & 28.3 & $-2.83+2.05$ & \\
\hline No & 287 & 71.7 & $-2.34+1.94$ & 0.030 \\
\hline \multicolumn{5}{|l|}{ Retinopathy } \\
\hline Yes & 170 & 42.5 & $-2.88+1.98$ & \\
\hline No & 230 & 57.5 & $-2.18+1.93$ & $<0.001$ \\
\hline \multicolumn{5}{|l|}{ Nephropathy } \\
\hline Yes & 43 & 10.8 & $-2.90+1.71$ & \\
\hline No & 357 & 89.2 & $-2.43+2.00$ & 0.142 \\
\hline \multicolumn{5}{|l|}{ Diabetic foot } \\
\hline Yes & 20 & 5.0 & $-3.36+2.02$ & \\
\hline No & 380 & 95.0 & $-2.39+1.95$ & 0.031 \\
\hline
\end{tabular}

$(\mathrm{p}<0.001)$. The worst QOL was expressed among poorly controlled diabetes while the best was among patients with excellent control. QoL of diabetics was worse among those who had diabetes complications, i.e., neuropathy $(p=0.03)$, especially retinopathy $(p<0.001)$, and diabetic foot $(p=0.031)$. However, difference was not significant according to nephropathy.

\section{Discussion}

This study showed that the majority of Saudi diabetic patients had non-favorable ADDQOL scores. More than one fifth of patients scored less than -4.0 (i.e., worst QOL).

It has been repeatedly and consistently stated that diabetes has detrimental effects on QOL. Diabetes has been stated to impair all dimensions of health [5] [7] [17].

This study showed that, as regard patients' personal characteristics, patients' age, education and occupation were not significant variables as regard their impact on QOL. On the other hand, female patients had significantly worse QOL. This sex-difference could be partly explained by the worse situation of female patients in respect to the disease and an evidence for gender inequalities in some communities.

In Riyadh, KSA, Abdel-Gawad (2002) [3] reported that males had significantly higher satisfaction. Similar difference in QOL of both genders was observed in a study conducted in Iran by Aghamollaei et al. (2003) [18]. In western countries, lower QOL in diabetic women was also reported by Rubin and Peyrot (2004) [9] in USA and Redekop et al. (2002) [19] in the Netherlands.

This study showed that married patients had significantly worse QOL compared with non-married patients. This finding may be explained by the fact that married diabetic people have more responsibilities and more persons to look after in addition to their disease, compared with those diabetics who are not married.

Laine and Caro (1996) [20] noted that hypoglycemia may harm the marital relationship, academic achieve- 
ment, and performance on the job. Under certain circumstances, both insulin and oral hypoglycemic agents can cause the blood glucose to fall below $40 \mathrm{mg} / \mathrm{dL}$. This stimulates counter-regulatory hormones, giving rise to a range of signs and symptoms, and functional impairment.

In KSA, Abdel-Gawad (2002) [3] stated that married patients reported significantly higher satisfaction, less impact, few worry and better total QOL. Less educated respondents reported significantly fewer worries than those of higher education. Interestingly, education played no independent role with respect to QOL.

Brown et al. (2000) [21] reported that neither gender, level of education nor age significantly affected the QOL associated with diabetes.

The present study showed that patients with type 2 diabetes had significantly worse QOL than those with type-1 diabetes. Moreover, QOL was worse among diabetics with less than 10 years duration of disease, followed by a relatively better QOL among those with 10 - 20 years and then the worse QOL was present among those with more than 20 years of diabetes.

Brown et al. (2000) [21] noted that the type of diabetes, length of time of diabetes seemed not to have an impact over QOL.

The degree of control of disease among diabetics was significantly and directly associated with their QOL (p $<0.001)$. The worst QOL was expressed among poorly controlled diabetes while the best was among patients with excellent control.

De Grauw et al. (2001) and Walling (2002) [22] [23] emphasized the importance of diabetes control. They stated that strict control of blood glucose levels in diabetic patients can result in a reduction of one fourth of microvascular complications.

The present study showed that complications of diabetes were very common, mainly retinopathy (42.5\%) or neuropathy (28.3\%). QOL of diabetics was less among those who had diabetes complications, especially retinopathy $(p<0.001)$, diabetic foot $(p=0.031)$ and neuropathy $(p=0.03)$. However, difference was not significant according to those with nephropathy.

Abolfotouh (1999) [24] stated that, as a complication of diabetes, neuropathy can cause numbness, foot drop, diarrhea, pain, and total erectile impotence. Woodcock et al. (2004) [25] noted that diabetic retinopathy is one of three serious microvascular complications of diabetes, the other two being diabetic neuropathy and diabetic nephropathy.

Al-Khader (2001) [26] stated that there are no precise data available on the incidence of nephropathy in Saudi diabetics. What is known is that the vast majority of Saudi diabetics entering dialysis (96\%) are of Type 2. In a study of a diabetes outpatient clinic, $12.8 \%$ of patients had dipstick proteinuria and of the remaining patients 41.3\% had microalbuminuria [27]. Al-Khader (2001) [26] warned that, with the growing magnitude of diabetic nephropathy, sooner or later the KSA is going to face a 'medical catastrophe' at dialysis units.

The presence of diabetic complications, such as retinopathy, peripheral vascular disease, coronary artery disease, peripheral sensory neuropathy, and depression, has been associated with poorer QOL in a number of studies [21] [28].

Tennvalla and Apelqvistb (2000) [29] reported that patients with current foot ulcers experience lower QOL than those who have healed primarily without any amputation.

Benbow et al. (1998) [30] noted that painful diabetic neuropathy has a considerable impact on QOL. Pain was associated with a reduction in sleep, walking and ability to perform domestic duties. It has been shown that when chronic diabetic neuropathic pain is reduced there is an associated increase in exercise tolerance and better QOL.

In conclusion, QOL of Saudi adult diabetic patients is not favorable, personal characteristics associated with worse QOL among diabetics include female gender, and being married, disease characteristics associated with worse QOL among diabetics include being a type 1 diabetic and those with uncontrolled diabetes (i.e., $>\mathrm{HbA}_{1 \mathrm{c}}>$ 8), and the main complications associated with worse QOL among diabetics include retinopathy, diabetic foot and neuropathy.

It is recommended that the health care team for diabetics (e.g., nurses, general practitioners, diabetologists, podiatricians, etc) should not be only disease-centered, QOL of the diabetic patient should always be regularly assessed and improved accordingly. The presence of one or more risk factors associated with poorer QOL among diabetics should attract the attention of health care providers to be assessed and managed, health education of diabetic patients should be fully and regularly implemented to cover the importance of improving their QOL, proper diabetes control should be enforced, and reasons for suboptimal diabetes control should be inves- 
tigated and managed accordingly.

\section{References}

[1] Haas, B.K. (1999) A Multidisciplinary Concept Analysis of Quality of Life. Western Journal of Nursing Research, 21, 728. http://dx.doi.org/10.1177/01939459922044153

[2] Wee, H., Cheung, Y., Li, S., Fong, K. and Thumboo, J. (2005) The Impact of Diabetes Mellitus and Other Chronic Medical Conditions on Health-Related Quality of Life: Is the Whole Greater than the Sum of Its Parts? Health and Quality of Life Outcomes, 3, 2. http://dx.doi.org/10.1186/1477-7525-3-2

[3] Abdel-Gawad, E.S. (2002) Quality of Life in Saudis with Diabetes. Saudi Journal of Disability and Rehabilitation, 8, 163-168

[4] Al-Nozha, M.M., Al-Maatouq, M.A., Al-Mazrou, Y.Y., Al-Harthi, S.S., Arafah, M.R., Khalil, M.Z., Khan, N.B., Al-Khadra, A., Al-Marzouki, K., Nouh, M.S., Abdullah, M., Attas, M., Al-Shahid, M.S. and Al-Mobeireek, A. (2004) Diabetes Mellitus in Saudi Arabia. Saudi Medical Journal, 25, 1603-1610.

[5] Reddy, S.S. () Health Outcomes in Type 2 Diabetes. International Journal of Clinical Practice, Supplement, 113, 46-53.

[6] Stewart, A.L., Greenfield, S., Hays, R.D., Wells, K., Rogers, W.H., Berry, S.D., McGlynn, E.A. and Ware, Jr., J.E. (1989) Functional Status and Well-Being of Patients with Chronic Conditions. Results from the Medical Outcomes Study. JAMA, 262, 907-913. http://dx.doi.org/10.1001/jama.1989.03430070055030

[7] Alonso, J., Ferrer, M., Gandek, B., Ware, Jr., J.E., Aaronson, N.K., Mosconi, P., Rasmussen, N.K., Bullinger, M., Fukuhara, S., Kaasa, S., Leplege, A., IQOLA Project Group (2004) Health-Related Quality of Life Associated with Chronic Conditions in Eight Countries: Results from the International Quality of Life Assessment (IQOLA) Project. Quality of Life Research, 13, 283-298. http://dx.doi.org/10.1023/B:QURE.0000018472.46236.05

[8] Sprangers, M.A., de Regt, E.B., Andries, F., van Agt, H.M., Bijl, R.V., de Boer, J.B., Foets, M., Hoeymans, N., Jacobs, A.E., Kempen, G.I., Miedema, H.S., Tijhuis, M.A. and de Haes, H.C. (2000) Which Chronic Conditions Are Associated with Better or Poorer Quality of Life? Journal of Clinical Epidemiology, 53, 895-907. http://dx.doi.org/10.1016/S0895-4356(00)00204-3

[9] Rubin, R.R. and Peyrot, M. (2004) Quality of Life and Diabetes. Diabetes/Metabolism Research and Reviews, 15, 205-218. http://dx.doi.org/10.1002/(SICI)1520-7560(199905/06)15:3<205::AID-DMRR29>3.0.CO;2-O

[10] Vileikyte, L., Leventhal, H., Gonzalez, J.S., Peyrot, M., Rubin, R.R., Ulbrecht, J.S., Garrow, A., Waterman, C., Cavanagh, P.R. and Boulton, A.J (2005) Diabetic Peripheral Neuropathy and Depressive Symptoms: The Association Revisited. Diabetes Care, 28, 2378-2383. http://dx.doi.org/10.2337/diacare.28.10.2378

[11] Goodridge, D., Trepman, E. and Embil, J.M. (2005) Health-Related Quality of Life in Diabetic Patients with Foot Ulcers: Literature Review. Journal of Wound, Ostomy \& Continence Nursing, 32, 368-377. http://dx.doi.org/10.1097/00152192-200511000-00007

[12] Garratt, A.M., Schmidt, L. and Fitzpatrick, R. (2002) Patient-Assessed Health Outcome Measures for Diabetes: A Structured Review. Diabetic Medicine, 19, 1-11. http://dx.doi.org/10.1046/j.1464-5491.2002.00650.x

[13] Ghanbari, A., Yekta, Z.P., Roushan, Z.A. and Lakeh, N.M. (2005) Assessment of Factors Affecting Quality of Life in Diabetic Patients in Iran. Public Health Nursing, 22, 311-322. http://dx.doi.org/10.1111/j.0737-1209.2005.220406.X

[14] Savli, H. and Sevinc, A. (2005) The Evaluation of the Turkish Version of the Well-Being Questionnaire (WBQ-22) in Patients with Type 2 Diabetes: The Effects of Diabetic Complications. Journal of Endocrinological Investigation, 28, 683-691. http://dx.doi.org/10.1007/BF03347550

[15] Bradley, C., Todd, C., Gorton, T., Symonds, E., Martin, A. and Plowright, R. (1999) The Development of an Individiualised Questionnaire Measure of Perceived Impact of Diabetes on Quality of Life: The ADDQOL. Quality of Life Researcher, 8, 79-91. http://dx.doi.org/10.1023/A:1026485130100

[16] Al-Shammari, S.A., Nass, M., Al-Maatouq, M.A. and Al-Quaiz, J.M. (1996) Family Practice in Saudi Arabia: Chronic Mortality and Quality of Care. International Journal Quality in Health Care, 8, 383-387. http://dx.doi.org/10.1093/intqhc/8.4.383

[17] Harris, M.I. (2000) Health Care and Health Status and Outcomes for Patients with Type 2 Diabetes. Diabetes Care, 23, 754-758. http://dx.doi.org/10.2337/diacare.23.6.754

[18] Aghamollaei, T., Eftekhar, H., Shojaeizadeh, D., Mohammad, K., Nakhjavani, M. and Ghofrani, P.F. (2003) Behavior, Metabolic Control and Health-Related Quality of Life in Diabetic Patients at Bandar Abbas Diabetic Clinic. Iranian Journal of Public Health, 32, 54-59.

[19] Redekop, W.K., Koopmanschap, M.A., Stolk, R.P., Rutten, G.E., Wolffenbuttel, B.H. and Niessen, L.W. (2002) Health-Related Quality of Life and Treatment Satisfaction in Dutch Patients with Type 2 Diabetes. Diabetes Care, 25, 458-463. http://dx.doi.org/10.2337/diacare.25.3.458 
[20] Laine, C. and Caro, J.F. (1996) Preventing Complications in Diabetes Mellitus. The Role of Primary Care Physician. Medical Clinics of North America, 80, 457-473. http://dx.doi.org/10.1016/S0025-7125(05)70448-X

[21] Brown, G.C., Brown, M.M., Sharma, S., Brown, H., Gozum, M. and Denton, P. (2000) Quality of Life Associated with Diabetes Mellitus in an Adult Population. Journal of Diabetes and Its Complications, 14, 18-24. http://dx.doi.org/10.1016/S1056-8727(00)00061-1

[22] de Grauw, W.J., van de Lisdonk, E.H., van Gerwen, W.H., van den Hoogen, H.J. and van Weel, C. (2001) Insulin Therapy in Poorly Controlled Type 2 Diabetic Patients: Does It Affect Quality of Life? British Journal of General Practice, 51, 527-532.

[23] Walling, A.D. (2002) Type 2 Diabetes Quality of Life and Early Insulin Therapy. American Family Physician, 65, 4.

[24] Abolfotouh, M.A. (1999) Effect of Diabetes Mellitus on Quality of Life: A Review. Special Communication. Annals of Saudi Medicine, 19, 518-524.

[25] Woodcock, A., Bradley, C., Plowright, R., Ffytche, T., Kennedy-Martin, T. and Hirsch, A. (2004) The Influence of Diabetic Retinopathy on Quality of Life. Interviews to Guide the Design of a Condition-Specific, Individualised Questionnaire: The RetDQoL. Patient Education and Counseling, 53, 365-383. http://dx.doi.org/10.1016/j.pec.2003.10.007

[26] Al-Khader, A.A. (2001) Impact of Diabetes in Renal Diseases in Saudi Arabia. Nephrology Dialysis Transplantation, 16, 2132-2135. http://dx.doi.org/10.1093/ndt/16.11.2132

[27] Al-Zaid, A., Sobki, S. and De Silva, V. (1994) Prevalence of Microalbuminuria in Saudi Arabians with Non-InsulinDependent Diabetes Mellitus: A Clinic Based Study. Diabetes Research and Clinical Practice, 26, 115-120. http://dx.doi.org/10.1016/0168-8227(94)90148-1

[28] Lloyd, A., Sawyer, W. and Hopkinson, P. (2001) Impact of Long-Term Complications on Quality of Life in Patients with Type 2 Diabetes Not Using Insulin. Value in Health, 4, 392-400. http://dx.doi.org/10.1046/j.1524-4733.2001.45029.x

[29] Tennvalla, G.R. and Apelqvistb, J. (2000) Health-Related Quality of Life in Patients with Diabetes Mellitus and Foot Ulcers. Journal of Diabetes and Its Complications, 14, 235-241. http://dx.doi.org/10.1016/S1056-8727(00)00133-1

[30] Benbow, S.J., Wallymahmed, M.E. and MacFarlane, I.A. (1998) Diabetic Peripheral Neuropathy and Quality of Life. QJM, 91, 733-737. http://dx.doi.org/10.1093/qjmed/91.11.733 
Scientific Research Publishing (SCIRP) is one of the largest Open Access journal publishers. It is currently publishing more than 200 open access, online, peer-reviewed journals covering a wide range of academic disciplines. SCIRP serves the worldwide academic communities and contributes to the progress and application of science with its publication.

Other selected journals from SCIRP are listed as below. Submit your manuscript to us via either submit@scirp.org or Online Submission Portal.
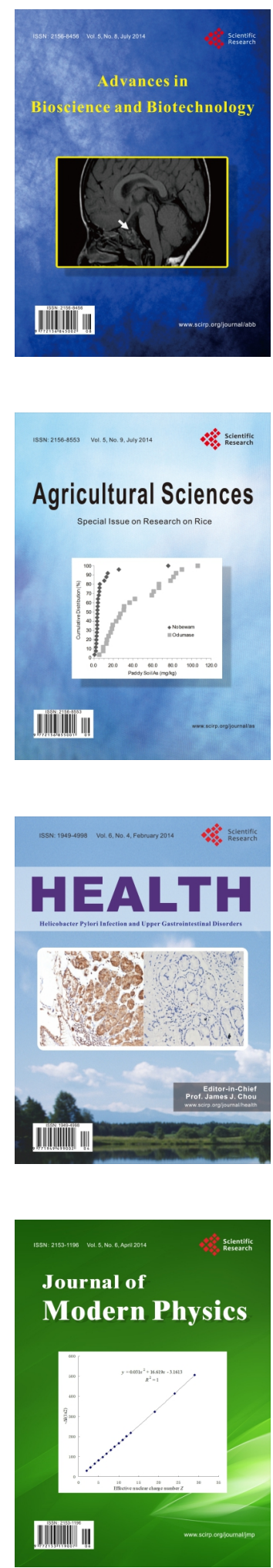
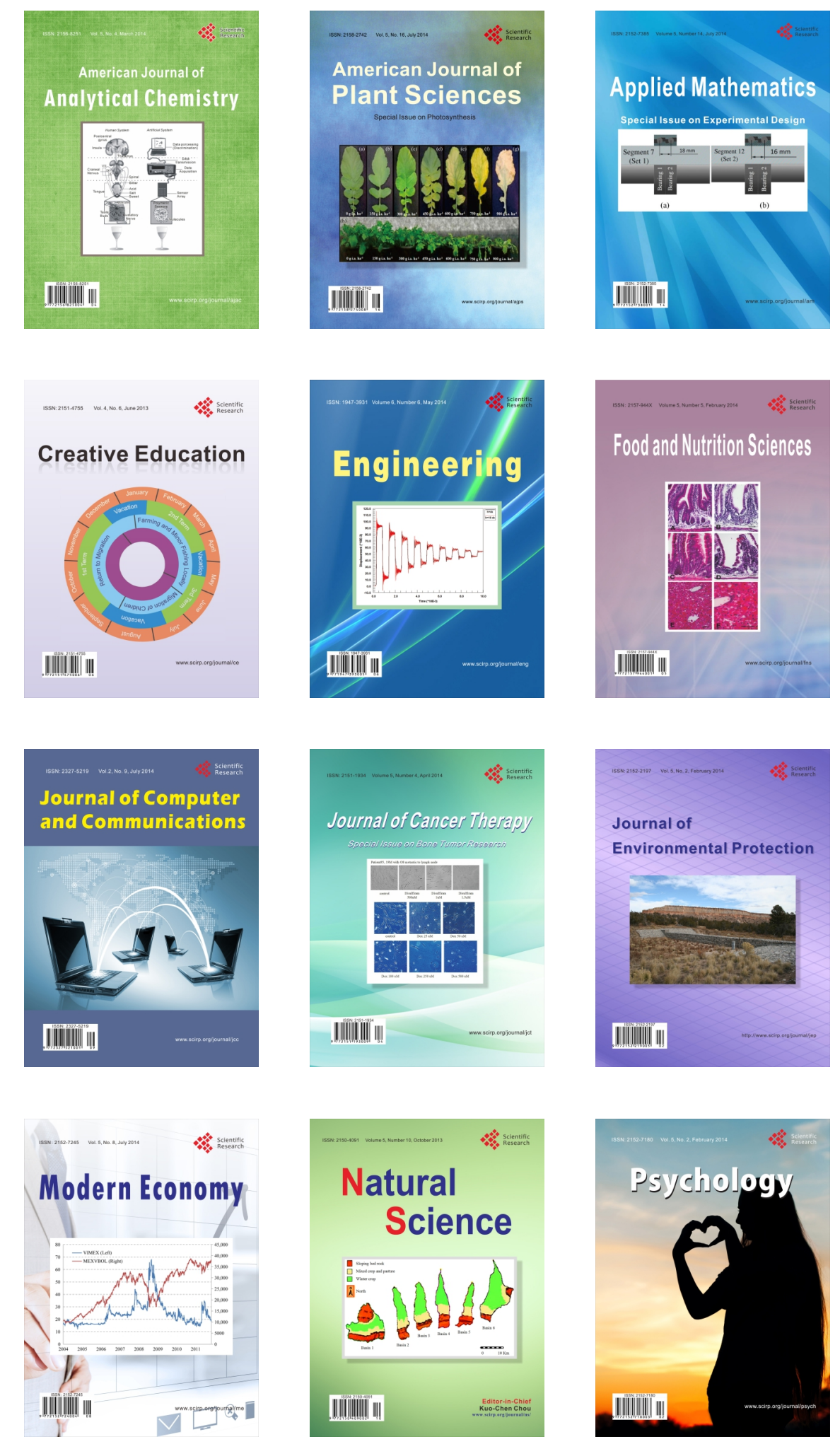